\title{
EMENDA CONSTITUCIONAL № 95/2016: Ameaças e Desafios aos Institutos Federais
}

\author{
Adriana Clarice Henning ${ }^{1}$ \\ Letícia Ramalho Brittes ${ }^{2}$
}

\section{RESUMO}

Este trabalho busca investigar os efeitos do congelamento dos gastos públicos, via Emenda Constitucional no 95/2016, no Ensino Médio integrado da Educação Profissional e Tecnológica (EPT). A partir de uma discussão teórica, busca apontar os avanços na Educação Profissional trazidos pelos Institutos Federais bem como os desafios que se colocam ante a aprovação da Emenda Constitucional no 95/2016. Considerando as concepções que dão origem ao debate sobre a construção de uma Educação Profissional e tecnológica emancipadora, na perspectiva do trabalho como princípio educativo e tendo a emancipação humana como horizonte, é possível fazer uma contextualização do momento pelo qual passa a Educação no país, servindo a um projeto de Estado e sociedade.

Palavras-chave: Gestão pública. Emenda Constitucional no 95/2016. Gerencialismo. Ensino Médio integrado.

\section{CONSTITUTIONAL AMENDMENT №. 95/2016: THREATS AND CHALLENGES TO FEDERAL INSTITUTES}

\begin{abstract}
This paper seeks at investigate the effects of the freeze on public spending, via Constitutional Amendment No. 95/2016, on the integrated high school of Vocational Education. Based on a theoretical discussion, it was pointed out the advances in Professional Education brought by the Federal Institutes as well as the challenges that face the approval of Constitutional Amendment $n=95 / 2016$. Considering the conceptions that give rise to the debate on the construction of an emancipatory Vocational Education, from the perspective of work as an educational principle and with human emancipation as a goal, it is possible to contextualize the moment that Education is going through in the country, serving the project of State and society. Keywords: Public management. Constitutional Amendment 95/2016. Managerialism. Integrated secondary education.
\end{abstract}

RECEBIDO EM: $27 / 2 / 2020$

ACEITO EM: 24/4/2020

\footnotetext{
${ }_{1}$ Autora correspondente. Instituto Federal Farroupilha - Campus Santo Ângelo. Rodovia RS-218 - Indubrás. CEP 98806-700. Santo Ângelo/ RS, Brasil. http://lattes.cnpq.br/8856903945664993. https://orcid.org/0000-0002-6145-8168. adrianahenning@gmail.com

2 Instituto Federal Farroupilha - Campus Santo Ângelo. Santo Ângelo/RS, Brasil. http://lattes.cnpq.br/5104573307305494. https://orcid. org/0000-0002-0279-2713. leticia.brittes@iffarroupilha.edu.br
} 
No ano de 2016 foi aprovada a Emenda Constitucional no 95/2016 (EC no 95/2016), também conhecida como Novo Regime Fiscal. Essa emenda constitucional tem por objetivo limitar os gastos públicos pelos próximos 20 anos, ou seja, até 2036, abrindo possibilidade de revisão após 10 anos. Sendo assim, a maior parte dos gastos do governo será reajustada, no máximo, pelo índice de inflação do ano anterior, posto que os gastos com Saúde e Educação estão contemplados nessa nova política.

Ao congelar o aumento real de investimentos em Educação, corre-se o risco de afetar a qualidade do ensino ofertado e a própria universalização do acesso ao ensino básico. Considerando que o ensino básico ainda não é universal e que a população aumenta a cada ano, na prática essa política representa uma retração na abrangência dos jovens em idade escolar, ou, na melhor das hipóteses, supre-se a necessidade de vagas, mas com o comprometimento da qualidade do ensino.

Cabe destacar que essa Emenda é fruto de um longo período de tentativas de reduzir o tamanho do Estado, desde a década de 90 do século 20, com o advento do neoliberalismo ${ }^{3}$, em que ocorre desmonte dos serviços públicos. A grande diferença do período anterior à aprovação da EC no 95/2016 e o posterior é que antes cada governo tinha liberdade para definir sua política econômica de maneira a dar maior prioridade aos gastos com Saúde e Educação, por exemplo, ou definir uma política de diminuição dos gastos primários, priorizando o pagamento da dívida pública. Após a aprovação da EC no 95/2016, no entanto, não cabe mais ao governo eleito essa definição, pois, por 20 anos, os gastos públicos não podem ultrapassar o teto estipulado na Emenda.

A grande problemática que se apresenta neste estudo são os efeitos do congelamento dos gastos públicos via Emenda Constitucional no 95/2016 no Ensino Médio integrado da Educação Profissional e Tecnológica. Considerando o vulto de uma política como a efetivada pela EC no 95/2016, torna-se fundamental realizar um estudo que mapeie os reais impactos do Novo Regime Fiscal na Educação.

Neste trabalho, trata-se, inicialmente, das concepções de Estado e como elas impactam na Educação; na sequência são apresentados os Institutos Federais e as particularidades e avanços que representam; seguindo, trata-se do financiamento da Educação e a Emenda Constitucional no 95/2016 e, por fim, são feitas considerações finais a partir das reflexões deste estudo.

\section{A EDUCAÇÃO REFÉM DOS MODELOS DE DESENVOLVIMENTO}

Ao realizar uma análise sobre a Educação é fundamental que se tenha em vista a que interesses esse projeto de educação está servindo. As diferentes concepções e projetos de educação têm, em sua essência, um objetivo político e uma proposta de sociedade a que deve atender. É no embate gerado pelas contradições sociais, historicamente definidas, que se moldam as políticas públicas para a Educação, conforme alerta Frigotto (2010)

Para mais informações ver SOARES, Laura Tavares. Os custos sociais do ajuste neoliberal na América Latina. São Paulo: Cortez, 2009. 
Um dos equívocos mais recorrentes nas análises da educação no Brasil, em todos os seus níveis e modalidades, tem sido o de tratá-la em si mesma e não como constituída e constituinte de um projeto, situado em uma sociedade cindida em classes, frações de classes e grupos sociais desiguais e com marcas históricas específicas (p. 25).

A educação brasileira passou por diversos momentos em termos de concepção e de objetivos. Há um pêndulo entre períodos em que a Educação é vista de maneira unitária e outros em que há um direcionamento para o mercado de trabalho. O projeto de educação posto em prática, no entanto, tem sido, normalmente, de caráter dualista, colocando a formação propedêutica separada da formação profissional, cindindo esses dois momentos da formação escolar. Ramos (2010) faz a defesa de um projeto de educação que une a formação do sujeito com a formação profissional, deslocando o foco do mercado de trabalho para a pessoa humana, proporcionando a formação de cidadãos críticos, preparados para a vida de maneira completa, em condições de ingressar no mercado de trabalho com as habilidades de aprender e compreender o processo produtivo em que estão inseridos.

\section{O contexto brasileiro}

No Brasil, ao analisar-se sua formação capitalista específica, fica evidente que se coloca perante o capitalismo mundial numa posição subordinada, de dependência e servidão. Isso deve ser considerado no momento de analisar o modelo educacional brasileiro, pois, para atender às demandas de mão de obra nessa divisão internacional do trabalho, não há necessidade da universalização do Ensino Médio de qualidade, isso porque a exigência do capital, conforme aponta Frigotto (2010, p. 35), é por trabalhadores manuais "de mãos adestradas ou olhos aguçados e coração e mente submissos", pois a produção econômica é predominantemente de baixo valor agregado, não tendo interesse, portanto, em formação de cidadãos críticos.

O projeto societário que se definiu, mormente na década de 1990, por um capitalismo monetarista e rentista, associado de forma subordinada e dependente aos centros hegemônicos do sistema capital, demanda dominantemente, na divisão internacional do trabalho, o trabalho simples e de baixo valor agregado. Consequentemente, para esse projeto de sociedade, não há necessidade da universalização e nem da democratização da qualidade da educação básica, especialmente de nível médio (FRIGOTTO, 2010, p. 35).

No momento de destinar recursos públicos para a Educação é que surge o embate histórico na definição da política econômica do governo: Estado neoliberal versus Estado desenvolvimentista. A política econômica do país sempre esteve dividida entre dois polos: os momentos de investimento público mais significativo, com maior distribuição de renda, e aqueles de redução da participação do Estado, com concentração de renda e retirada de direitos sociais.

No Brasil não se chegou a ter um Estado de Bem-Estar Social nos moldes do que ocorreu na Europa; o que se criou aqui foi uma imitação aquém nas conquistas sociais, chamado de Estado desenvolvimentista. O Estado desenvolvimentista, ou nacional desenvolvimentista, teve início no governo de Getúlio Vargas, tendo seu ápice no governo de Juscelino Kubitschek. Apesar do discurso nacionalista, o período militar já apresen- 
tou algumas medidas que iniciaram a desconstrução desse Estado desenvolvimentista, o que se intensificou a partir da década de 90 do século 20 com o surgimento do neoliberalismo.

O projeto do Estado desenvolvimentista tinha como base a construção de um Estado forte, atuante na Economia, garantindo alguns direitos sociais e trabalhistas e realizando investimentos públicos, fortalecendo a saúde e a educação, por exemplo. Nesse período da década de 90, no entanto, estava em franca expansão o neoliberalismo, o que representou uma guinada na conquista de direitos sociais universais. De acordo com Pires e Peroni (2019), não se vivenciou no país um Estado de Bem-Estar Social, mas, sim, um Estado desenvolvimentista sob direção do setor privado.

Com o governo de Fernando Collor de Mello potencializa-se o neoliberalismo no Brasil, o que significa uma reestruturação econômica e de intervenção do Estado, tendo como base os objetivos preconizados no Consenso de Washington ${ }^{4}$. Nesse momento o Estado passa a ser o grande vilão responsável pelos problemas enfrentados pela Economia Brasileira, como a baixa taxa de lucros, a alta da inflação, o desemprego, enfim, todas as mazelas sociais. Como saída para a crise era apresentado o modelo de modernização do Estado. Segundo Ramos (2014, p. 48), "dessa forma, a liberalização da economia tenderia a trazer o equilíbrio entre a produtividade, a modernidade e a prosperidade".

A política de reestruturação do Estado faz parte de um projeto maior, que tem por base a disputa de concepção de Estado. Conforme Paula (2005), entram em choque dois modelos antagônicos: a Administração Pública Gerencial e a Administração Pública Societal. De um lado tem-se a Administração Pública Gerencial, que centra a organização do Estado numa perspectiva de Estado-empresa, ou seja, a eficiência financeira do Estado é a prioridade; os aspectos sociais ficam em segundo plano; o objetivo principal é ter resultados financeiros positivos, exatamente a mesma lógica das empresas que são moldadas para buscar o lucro. Para que isso seja possível os mecanismos de participação popular são bastante restritos, tendo uma estrutura muito mais centralizada. Por outro lado, tem-se a Administração Pública Societal, em que as necessidades dos cidadãos estão no centro da agenda governamental, isto é, as pautas sociais e de melhoria da condição de vida e da participação cidadã nas decisões do governo norteiam toda a política do Estado.

É nesse embate entre concepções e modelos de Estado que ocorre a disputa pela hegemonia ${ }^{5}$, refletindo nos modelos a serem seguidos nas diversas áreas, como os de Educação, e o nível de financiamento que será destinado para sua concretização. A prioridade na alocação de recursos financeiros do Estado reflete uma escolha política sobre qual modelo de desenvolvimento busca-se para o país. Essa disputa de modelo de Esta-

\footnotetext{
O Consenso de Washington foi uma reunião convocada pelo Instituto Internacional de Economia, patrocinada pelo governo dos EUA, FMI e Banco Mundial, pelas transnacionais e pelos grandes bancos. Deliberaram como pontos centrais a abertura econômica, a desestatização, a desregulamentação e a flexibilização das relações de trabalho. Ver mais em SOUZA (2008), capítulo 9.

Hegemonia, segundo a concepção de Gramsci, é o domínio político, econômico, cultural e ideológico de uma classe social sob a outra; é a concretização do poder de uma classe sob a classe subalterna, quando os interesses da classe dominante são colocados como os interesses de toda a sociedade.
} 
do, todavia, não é algo dado. Apesar de uma concepção sobre seu papel na sociedade ser mais forte que outra, há uma disputa permanente sobre os rumos que tomará, conforme Hypólito (2008),

Muito embora as forças conservadoras e reacionárias, nas últimas décadas, tenham tido sucesso na articulação de sua hegemonia, isso não significa que o estado seja um ente monolítico. É preciso reconhecer as complexidades envolvidas nesse processo de hegemonia e considerar o estado como um território de contestações, no qual lutas por hegemonia ocorrem a todo o momento (p. 64).

Esse embate fica mais forte nos períodos de retração do Estado, que ocorre nos momentos de crise econômica, também conhecida como austeridade ${ }^{6}$, quando a arrecadação diminui, o que torna o cumprimento da meta fiscal mais difícil, fazendo com que se reduzam os gastos públicos. Outra medida adotada é a redução de salários, na tentativa de aumentar os lucros das empresas e sua competitividade. Ao reduzir, no entanto, os gastos do Estado e os gastos dos trabalhadores, que terão menos dinheiro para consumir, a demanda agregada ${ }^{7}$ também diminui. Ao abreviar o consumo reduz-se ainda mais a arrecadação, gerando o que Rossi e Dweck (2016) chamam de "círculo vicioso da austeridade", que ocorre quando cortes do gasto público potencializam a redução do crescimento econômico, que, por sua vez, provoca novas quedas da arrecadação, exigindo outros cortes de gasto.

\section{O desmonte dos serviços públicos}

Desde a redemocratização, o Brasil passa por um processo de disputa na definição do papel do Estado nas diversas áreas da sociedade. De um lado a mobilização social proveniente do processo de retomada da Democracia puxava o pêndulo para a construção de um Estado mais presente na sociedade, do outro o neoliberalismo estava em franca expansão, puxando o pêndulo para a construção de um Estado mínimo, segundo Antunes e Peroni (2017, p. 187) "com graves consequências para a construção da democracia e da efetivação dos direitos sociais, materializados em políticas públicas, dando lugar ao que temos chamado de 'naturalização do possível'".

Em um cenário de redução do tamanho do Estado, a Educação é sempre afetada, pois, conforme Apple (2005), não há uma boa escola sem condições adequadas de remuneração dos professores e sem as condições físicas e materiais, sala de aula equipada, recursos para aulas práticas e toda uma gama de necessidades que um ensino de qualidade exige. A não destinação de recursos financeiros suficientes para a Educação gera uma precarização que faz parte de um plano maior de privatização dos serviços públicos, afinal, quando um serviço público está ruim é mais fácil propagar o discurso de que é necessário privatizá-lo para resolver o problema. Teodoro (2011, p. 31) mostra que "as consequências dessa transferência de centro do discurso político estão presentes na agenda hegemônica das políticas públicas de educação contemporâneas". Nesse sentido, Apple (2005) alerta que

\footnotetext{
6 Em Economia, austeridade é entendida como um controle rígido dos gastos públicos para equilibrar as receitas e despesas do Estado.

Demanda agregada é toda a demanda existente em uma Economia em determinado período e nível de preços.
} 
[...] É preciso um trabalho ideológico criativo e de longo prazo e, ainda, as pessoas têm que ser forçadas a perceber tudo o que é público como "ruim" e o que é privado como "bom". E qualquer um que trabalhe nessas instituições públicas deve ser visto como ineficiente e necessitado da sensata realidade da competição [...] (p. 41-42).

Quando se pensa num projeto educacional não é possível desvinculá-lo de um projeto social mais amplo. Segundo Frigotto e Ciavatta (2003), o projeto educacional deve estar articulado com o desenvolvimento econômico nas esferas local, regional e nacional, com o desenvolvimento científico e com as políticas de geração de emprego e renda. Seguindo a mesma lógica, Sander (2005, p. 25) mostra que "existe abundante evidência empírica de que a Educação está diretamente relacionada com a formação cidadã, a preparação para o trabalho e a consecução do desenvolvimento humano sustentável com equidade social". Nesse sentido, a Educação deveria ter uma posição de prioridade na alocação de recursos públicos, no entanto Frigotto (2009, p. 74) mostra que não é isso que ocorre: "a não prioridade real da educação básica se reflete pelo pífio fundo público garantido para seu financiamento e pelos mecanismos paliativos, emergenciais ou protelatórios para construir um sistema nacional de educação".

O trabalho de desmonte dos serviços públicos, principalmente da Educação, entra numa lógica privatista em que o público tem por objetivo apenas servir o privado, ou seja, quando o Estado tem como função principal atender aos interesses das grandes empresas e corporações. Corroborando essa ideia, Apple (2005, p. 31) mostra que a reestruturação das instituições públicas tem por objetivo "assegurar que o Estado servisse a interesses de negócios; fazer com que as operações internas do Estado moldassem aquelas usadas nos negócios". Na medida em que a Educação fica refém dessa lógica, têm-se um quadro de dificuldade para o estabelecimento de um ensino de qualidade, conforme apontam Araújo e Frigotto (2015)

Mas, por outro lado, não reduzimos a possibilidade do ensino integrado a um ato de vontade dos docentes e dos gestores educacionais; compreendemos que este depende, também, das condições concretas de sua realização, argumentamos que a promoção de práticas pedagógicas integradoras requer a constituição de um ambiente material que a favoreça e da busca permanente pelo elemento integrador, considerando as realidades específicas, a totalidade social e os sujeitos envolvidos (p. 65).

Nessa lógica de privatização dos serviços públicos, a Educação enfrenta ataques em diversas frentes. Segundo Peroni e Scheibe (2017, p. 387), pode ocorrer por intermédio da "oferta direta de serviços educacionais por instituições privadas, como também por meio de políticas em que o privado disputa o conteúdo das políticas públicas educativas, como é o caso das parcerias público-privadas". Nesse sentido, Antunes e Peroni (2017, p. 186) apontam como sujeitos individuais e coletivos, com diferentes graus de organização, em diferentes âmbitos e com distintos graus de influência, o "setor financeiro, organismos internacionais, setor governamental".

Os organismos internacionais monitoram de perto a organização da Educação em diversos países, principalmente os considerados periféricos. Esse controle ocorre para garantir os interesses do capital internacional, como a Organização para a Cooperação 
e Desenvolvimento Econômico (OCDE), o Banco Mundial, o Banco Interamericano de Desenvolvimento (BID), além de conglomerados internacionais privados nesses países. Assim, a Educação estará a serviço de uma formação para as necessidades do mercado. Consoante Peroni e Scheibe (2017, p. 387-388), há diversas formas de realizar essa ingerência, como na "formação de professores, no monitoramento dos sistemas educativos, no patrocínio de avaliações internacionais, entre outras ações, para as quais são estabelecidas metas a serem cumpridas". Ainda sobre essa influência na definição do papel do Estado, Antunes e Peroni (2017) afirmam:

Assim, a globalização, principalmente a financeira, mas também a produtiva, com as mudanças nos mercados mundiais, não minimiza o papel do Estado, mas o redefine. Enfim, são mudanças profundas não apenas na produção, mas no modo de vida da sociedade. Entendemos que essas redefinições no papel do Estado modificam as fronteiras entre o público e o privado e materializam-se das mais variadas formas (p. 186).

Essa captura do Estado para atender aos interesses do capital, parte de um "pressuposto neoliberal de que não é o capitalismo que está em crise, mas o Estado" (PERONI; CAETANO, 2015, p. 339). Para Peroni e Scheibe (2017, 389), é nesses momentos de retração do papel do Estado que os "avanços conquistados correm risco de um retrocesso pragmático no qual o mercado justifica a sua atuação no público para formar um sujeito instrumental à reestruturação produtiva". Com essa concepção em mente fica fácil inserir na agenda econômica do governo a necessidade de "reformar" o Estado para superar a crise, tornando-o mais eficiente e produtivo.

\section{A EDUCAÇÃO PROFISSIONAL DE NÍVEL MÉDIO E OS INSTITUTOS FEDERAIS}

No contexto de necessidade de formação profissional, exigida pelo mercado de trabalho, têm-se um poderoso instrumento que são os Institutos Federais de Educação, Ciência e Tecnologia, no entanto estas instituições colocam uma possibilidade de atender essa formação técnica aliada com a formação humana. Criados pela Lei 11.892 de 29 de dezembro de 2008, esses espaços de formação representam um avanço no sentido de proporcionarem carreiras e estruturas adequadas para o desenvolvimento de uma educação de qualidade rumo a uma educação politécnica.

As portas que os Institutos Federais abrem para o país são a possibilidade de construção de ciência e tecnologia nacionais, rompendo com a dependência tecnológica de nações desenvolvidas. Conforme Frigotto e Ciavatta (2003, p. 102-103), "a educação é tanto um direito social básico e universal quanto vital para romper com a histórica dependência científica, tecnológica e cultural do país". Nesse sentido, a construção de um modelo de Educação emancipador é "fundamental para a construção de uma nação autônoma, soberana e solidária na relação consigo mesma e com outras nações".

A criação dos Institutos Federais representa um passo na constituição de uma alternativa educacional ao modelo tecnicista, democratizando o acesso ao ensino público de qualidade por meio do aumento na oferta de vagas, principalmente no ensino técnico profissionalizante, e criação de novas unidades no interior do país. Segundo o Conselho Nacional das Instituições da Rede Federal de Educação Profissional, Científica e Tecnológica (Conif), existem, atualmente, 38 Institutos Federais, 2 Centros Federais de 
Educação Tecnológica (Cefets) e o Colégio Pedro II, que, juntos, integram a Rede Federal de Educação Profissional, Científica e Tecnológica, também chamada simplesmente de Rede Federal.

\section{A proposta dos Institutos Federais}

Desde a retomada democrática da sociedade brasileira a Educação Profissional passou por diversas formulações, que ora direcionavam para a formação de mão de obra para o mercado de trabalho, desvinculada da Educação Básica, ora articulava formação propedêutica e formação profissional. O primeiro movimento de alteração legal ocorreu com a Lei n. 8.948/94, que instituiu o Sistema Nacional de Educação Tecnológica e transformação das Escolas Técnicas Federais em Centros Federais de Educação Tecnológica; seria a efetivação do Sistema Nacional de Educação Tecnológica e dos Cefets nos termos da Lei.

Em 1996, já no governo de Fernando Henrique Cardoso, foi aprovada a Lei $n$. 9.394/96, que incorporou a Educação Profissional como processo educacional específico, não vinculado necessariamente a etapas de escolaridade, voltado para o permanente desenvolvimento de aptidões para a vida produtiva. Já no ano seguinte, o Decreto n. 2.208/97 instituiu a separação curricular entre o Ensino Médio e a Educação Profissional mediante a regulamentação dos artigos 39 a 42 e o parágrafo 20 do artigo 36 da LDB, quando os níveis para a Educação Profissional foram definidos como básico, técnico e tecnológico. Segundo Ramos (2014), "o nível técnico destinava-se a proporcionar habilitação profissional a alunos matriculados ou egressos de ensino médio, devendo ter organização curricular própria e independente do primeiro".

A partir de 2002, com a eleição de Luiz Inácio Lula da Silva, ocorre um movimento de redirecionamento da Educação Profissional. O Decreto n. 5.154/2004, que revogou o Decreto n. 2.208/97, buscou restabelecer os princípios norteadores de uma política de Educação Profissional articulada com a Educação Básica. O Parecer n. 39/2004, da Câmara de Educação Básica do Conselho Nacional de Educação, no entanto, apesar de reconhecer a forma integrada como um curso único, considera que os conteúdos do Ensino Médio e os da Educação Profissional de nível técnico são de naturezas diversas, ou seja, mantém-se a dicotomia entre a formação para a cidadania e a formação para o mercado de trabalho.

Já no ano de 2005 é instituído o Programa Nacional de Integração da Educação Profissional com a Educação Básica na Modalidade de Educação de Jovens e Adultos (Proeja) na esfera federal, mediante o Decreto n. 5.478/2005. Este Programa abrangeria cursos e programas de Educação Profissional de formação inicial e continuada e técnica de nível médio, destinada à Educação de Jovens e Adultos. Já o Decreto n. 5.840/2006 ampliou o Proeja para todos os sistemas de ensino. Outro Programa criado neste período foi o Programa Brasil Profissionalizado, por meio do Decreto n. 6.302/2007, tendo os sistemas estaduais como foco, visando a apoiá-los na introdução da Educação Profissional Integrada ao Ensino Médio.

Com a Lei n. 11.741/2008 os termos do Decreto n. 5.154/2004 foram incorporados na Lei de Diretrizes e Bases da Educação Nacional (LDB). No mesmo ano, pela Lei $n$. 11.892/2008 foi instituída a Rede Federal de Educação Profissional, Científica e Tecno- 
lógica, criando os Institutos Federais de Educação, Ciência e Tecnologia, definidos como instituições de Educação Superior, básica e profissional, pluricurriculares e multicampi, especializados na oferta de Educação Profissional e tecnológica nas diferentes modalidades de ensino, com base na conjugação de conhecimentos técnicos e tecnológicos com as suas práticas pedagógicas. Conforme Eliezer Pacheco (2011)

Como resultado desses debates, a Lei no 11.892, publicada em 29/12/2008, cria no âmbito do Ministério da Educação um novo modelo de instituição de educação profissional e tecnológica. Estruturados a partir do potencial instalado nos Cefets, escolas técnicas e agrotécnicas federais e escolas vinculadas às universidades federais, os novos Institutos Federais de Educação, Ciência e Tecnologia geram e fortalecem condições estruturais necessárias ao desenvolvimento educacional e socioeconômico brasileiro (p. 49).

A Rede Federal ${ }^{8}$ possui diversas modalidades de ensino, contemplando desde cursos de Formação Inicial e Continuada (FIC) e Ensino Médio Profissionalizante, que podem ser integrados, concomitantes, subsequentes ou específicos para a formação de jovens e adultos por meio do Proeja, até cursos superiores e Pós-Graduação. A oferta de vagas deve obedecer à seguinte proporção: $50 \%$ das vagas para cursos técnicos de nível médio profissionalizantes e $20 \%$ das vagas para cursos de Licenciatura. Dessa forma, pode-se observar que o foco da Rede Federal está na formação de nível médio profissionalizante.

Os Institutos Federais também são caracterizados por possuírem uma estrutura multicampi, focando na interiorização da Educação Profissional e tendo como objetivo central o compromisso com o desenvolvimento regional. Nessa perspectiva, o desenvolvimento da cidadania e a criação de oportunidades de alavancar as diversas regiões do país, tanto econômica quanto socialmente, está entre as prioridades dos Institutos Federais. Nesse sentido, segundo Pacheco (2011, p. 21), "o desenvolvimento local, regional ou nacional não pode prescindir do domínio, da produção e da democratização do conhecimento", ou seja, a produção e a socialização do conhecimento são fundamentais no processo de emancipação dos espaços em que os Institutos Federais estão inseridos.

Já na concepção pedagógica, possui o trabalho como princípio educativo e a emancipação humana como horizonte. Ou seja, contempla os princípios básicos para a construção de uma educação politécnica, proporcionando uma formação crítica e unitária. Nas palavras de Pacheco $(2011$, p. 15): "agregar à formação acadêmica a preparação para o trabalho (compreendendo-o em seu sentido histórico, mas sem deixar de afirmar seu sentido ontológico)". Outra característica dos Institutos Federais é a transversalidade entre Educação e Tecnologia e verticalização dos diferentes níveis de escolaridade, proporcionando uma formação mais completa. Esta proposta de Ensino apresenta a indissociabilidade entre a formação para o trabalho e a formação para a vida, No entendimento de Pacheco (2011),

Neste trabalho, Institutos Federais e Rede Federal serão tratados como sinônimos de Rede Federal de Educação Profissional, Científica e Tecnológica. 
O que está em curso, portanto, reafirma que a formação humana, cidadã, precede a qualificação para a laboralidade e pauta-se no compromisso de assegurar aos profissionais formados a capacidade de manter-se em desenvolvimento. Assim, a concepção de educação profissional e tecnológica que deve orientar as ações de ensino, pesquisa e extensão nos Institutos Federais baseia-se na integração entre ciência, tecnologia e cultura como dimensões indissociáveis da vida humana e, ao mesmo tempo, no desenvolvimento da capacidade de investigação científica, essencial à construção da autonomia intelectual (p. 16).

Ainda, conforme o autor, o papel central dos Institutos Federais está na incorporação de setores sociais historicamente excluídos econômica e socialmente. Esse papel social da Rede Federal resgata o compromisso com a cidadania e transformação social, buscando uma formação humana com vistas à superação da exploração e da desigualdade social. Essa proposta educacional só é possível graças à infraestrutura da Rede Federal, garantindo instalações físicas adequadas, como salas de aula, laboratórios, biblioteca, salas especializadas, equipamentos tecnológicos e recursos para custeio de aulas práticas e saídas de campo, constituindo um conjunto fundamental para uma Educação de qualidade. Para garantir esse ambiente fértil à formação humana, no entanto, é necessário que haja garantia de recursos financeiros adequados, pois uma Educação de qualidade não ocorre sem investimento público suficiente.

\section{A EMENDA CONSTITUCIONAL № 95/2016 E O FINANCIAMENTO DA EDUCAÇÃO PROFISSIONAL E TECNOLÓGICA}

No ano de 2016 foi aprovada a Emenda Constitucional no 95/2016, também conhecida como o Novo Regime Fiscal. O ponto central dessa Emenda é o congelamento dos gastos públicos por 20 anos, permitindo apenas a reposição da inflação por meio da correção dos valores pelo Índice Nacional de Preços ao Consumidor Amplo (Ipca). Ou seja, os gastos públicos não terão aumentos reais nesse período, independentemente da situação econômica do país ou das necessidades da população, contribuindo para uma piora na qualidade dos serviços públicos ofertados.

A EC no 95/2016 faz parte de um pacote maior de medidas que visam à promoção de superavit primário ${ }^{9}$ para a recuperação econômica. Pode-se citar como exemplo desse pacote maior a reforma trabalhista, previdenciária, administrativa e tributária, entre outras, o que torna o cenário ainda mais nefasto aos trabalhadores brasileiros. Segundo Barbosa Filho (2017, p. 57), "a consolidação gradual e a imposição do teto de gastos acompanhada por uma reforma da previdência são passos importantes nessa direção", referindo-se à recuperação econômica, e acrescenta ainda (ibid., p. 58): "a flexibilização do mercado de trabalho e a permissão da terceirização são outras medidas com potencial de aumentar a produtividade doméstica".

É nesse cenário de retirada de direitos básicos e ataque aos serviços públicos que o financiamento da Educação Profissional e Tecnológica (EPT) precisa ser debatido. A constituição de uma Educação Profissional pública, gratuita e de qualidade é passo fun-

Superavit primário é o resultado positivo de todas as receitas e despesas do governo, excetuando gastos com pagamento de juros da dívida pública. 
damental para a promoção de melhores condições de vida e cidadania aos jovens brasileiros. Sua garantia, mais do que um incentivo para o desenvolvimento profissional, é uma necessidade para o pleno desenvolvimento do sujeito e para a promoção da redução da desigualdade social.

\section{A Emenda Constitucional no 95/2016}

No Brasil, diante da crise econômica e política, agravada a partir de 2014, surge a oportunidade de inserir na pauta econômica do governo a necessidade de instituir um novo regime fiscal que promova cortes no gasto público de maneira sistemática, objetivando um "reequilíbrio" das contas públicas ${ }^{10}$. Esse Novo Regime Fiscal tramitou na Câmara dos Deputados como Proposta de Emenda Constitucional no 241 (PEC 241) e no Senado Federal como Proposta de Emenda Constitucional no 55 (PEC 55), sendo aprovado como Emenda Constitucional no 95/2016 (EC no 95/2016). Em linhas gerais, a EC $\mathrm{n}$-95/2016 congelou os gastos públicos por 20 anos, ou seja, nesse período haverá somente a correção da inflação, por meio do IPCA, tendo como ano-base os gastos de 2016, não ocorrendo aumento real nos gastos públicos das áreas abrangidas pela Emenda. A EC no 95/2016 prevê, ainda, que, a partir de dez anos de execução do Novo Regime Fiscal, poderá haver uma revisão, que se limitará à alteração do índice adotado para correção inflacionária.

No caso específico da Saúde e Educação o ano-base adotado foi de $2017^{11}$, e, a partir de então, haverá somente a correção inflacionária. Essas áreas também possuem outra exceção, os gastos podem ser superiores à meta, desde que o gasto total do governo fique dentro do limite posto, ou seja, para que Saúde e Educação tenham aumento real é necessário que outra área tenha redução de gastos. A EC no 95/2016 não leva em consideração o aumento do Produto Interno Bruto (PIB) nem o aumento demográfico, o que gera distorções significativas no atendimento à população, uma vez que o crescimento de pessoas que necessitam desses serviços não terá contrapartida na ampliação dos recursos financeiros necessários, conforme alertam Rossi e Dweck (2016):

Em síntese, o Novo Regime Fiscal implica um congelamento real das despesas totais do Governo Federal que pressupõe uma redução do gasto público relativamente ao Produto Interno Bruto (PIB) e ao número de habitantes. Ou seja, de acordo com a regra proposta, os gastos públicos não vão acompanhar o crescimento da renda e da população (p. 1).

Considerando o crescimento demográfico e o atendimento já deficiente em Saúde e Educação, não se vê qualquer perspectiva de melhora nessas áreas. Conforme destaca Mariano (2017), quanto mais o governo investe em serviços públicos menos a população gasta na iniciativa privada comprando esses mesmos serviços. Ainda de acordo com Rossi e Dweck (2016), o Novo Regime Fiscal não é um plano de estabilização fiscal mas,

\footnotetext{
$\overline{{ }^{10} \text { Mariano (2017) }}$ alerta que as forças do capitalismo central aproveitam as situações de crise para assaltar os interesses públicos nacionais e locais, incentivando reformas a favor do livre-mercado que levam ao aprofundamento das crises, das desigualdades e da violência.

${ }^{11}$ A EC no 95/2016 estipula que em 2017 os gastos com Saúde e Educação serão fixados em 15\% e 18\% da receita corrente líquida, respectivamente.
} 
sim, um projeto de redução do tamanho do Estado, e representa, portanto, uma concepção do seu papel, quando os serviços básicos não são universais nem precisam ser de qualidade, abrindo, assim, novos mercados à iniciativa privada.

Nesse ponto cabe um destaque. O Novo Regime Fiscal precisou tramitar como uma proposta de emenda constitucional por um único motivo: a desvinculação das receitas destinadas à Saúde e Educação. Ou seja, as áreas mais afetadas, e que possuíam garantia constitucional, são exatamente as mais básicas ao atendimento à população. Outro fator a ser considerado é o engessamento da política econômica, tirando dos cidadãos a possibilidade de escolherem seus representantes com base em seus projetos para investimentos públicos, ou seja, os programas de governo não poderão ser aplicados caso confrontem o teto estipulado pela EC n 95/2016, conforme destaca Mariano (2017)

O novo regime fiscal suspende, por consequência, o projeto constituinte de 1988, e retira dos próximos governantes a autonomia sobre o orçamento, salvo se houver, no futuro, em uma nova gestão, outra proposta de emenda constitucional em sentido contrário. Retira também do cidadão brasileiro o direito de escolher, a cada eleição, o programa de governo traduzido no orçamento e, com isso, decidir pelas políticas públicas prioritárias para o desenvolvimento econômico (p. 261).

Ao desvincular os gastos públicos de qualquer relação com o crescimento econômico, a longo prazo ocorre uma retração desses gastos em relação ao PIB. Rossi e Dweck (2016) fazem uma simulação de como os gastos com Saúde e Educação reduziriam em relação ao PIB em 20 anos. Considerando uma taxa de crescimento do PIB de 2,5\% ao ano ${ }^{12}$, acompanhado da receita corrente líquida, com o congelamento das despesas com Saúde e Educação, estas passarão de 4\% do PIB em 2015 para 2,7\% do PIB em 20 anos. A EC no 95/2016 estipula que em 2017 os gastos com Saúde serão de 15\% da receita corrente líquida e os gastos com Educação de $18 \%$ da receita corrente líquida. $A$ partir de então ambos serão corrigidos pelo IPCA. Observando a simulação feita pelos autores, em 2036 estes mesmos gastos passariam a corresponder a 9,4\% e 11,3\% da receita corrente líquida, respectivamente.

Esse cenário que o Novo Regime Fiscal coloca ao Brasil torna-se ainda mais preocupante quando comparado com os países desenvolvidos onde, segundo Mariano (2017), é gasto, em proporção ao PIB, em torno de três vezes mais para assegurar serviços públicos de qualidade. Levando em conta os gastos com Educação, segundo a OCDE, o Brasil ocupa o penúltimo lugar em relação ao número de alunos contemplados, como mostra Mariano (2017):

Quer dizer, segundo dados da OCDE, dentro dos gastos públicos totais do Brasil, a educação até que recebe uma atenção grande, superando a média da OCDE. Porém, quando se divide o gasto pelo total de alunos, o país fica em penúltimo lugar. $\mathrm{O}$ alto grau de repetência e evasão acaba inflando o número de alunos e a baixa qualidade do ensino público também sobrecarrega o sistema (p. 269).

${ }^{12}$ A média dos últimos 20 anos para o crescimento do PIB foi de $3 \%$. 
A priorização do pagamento dos juros e amortizações da dívida pública não é novidade. Em cada governo ele ocupa maior ou menor espaço de acordo com a orientação política do mesmo. Para os defensores dessa política econômica, no entanto, no momento de justificar para a população, um argumento torna-se predominante: a comparação com a economia doméstica. Considerando o pouco conhecimento sobre os mecanismos econômicos que a maioria da população possui, torna-se fácil comparar com a situação financeira de suas famílias, no entanto um país não é uma família; cortar gastos para pagar dívidas pode ser uma boa estratégia para uma unidade familiar, mas para uma economia inteira significa deixar de investir em áreas que trarão reflexo no futuro. Podemos ver um exemplo dessa argumentação com Machado Segundo (2017),

Além disso, o pagamento da dívida pública, se no curto prazo parece privilegiar rentistas em detrimento de quem precisa da saúde e da educação públicas, no longo prazo poderá reconduzi-la a patamares significativamente mais baixos, permitindo assim uma redução dos recursos públicos anualmente comprometidos com o pagamento de juros. Fazendo-se uma comparação com a vida financeira de um cidadão, pode-se dizer que o pagamento da dívida do cheque especial permite a ele, nos meses subsequentes, deixar de gastar tanto com os elevadíssimos juros inerentes a essa modalidade de empréstimo, investindo os recursos obtidos a partir de então em finalidades consideradas mais importantes (2017, p. 36).

É importante ressaltar que quando uma família deixa de consumir para utilizar aquele dinheiro para pagar suas dívidas ela não é afetada pela redução no consumo, exceto por ficar privada desses produtos. Numa economia, o governo não é só consumidor. No momento em que ele deixa de gastar ele reduz a demanda de produtos que são fabricados por esse mesmo país. Ao reduzir o consumo pode afetar os empregos; pessoas desempregadas consomem menos, e, quanto menor o consumo, e por consequência a produção, menor o nível de impostos recolhidos e menor é a receita do governo. Diminuindo a receita é necessário, por essa lógica, cortar ainda mais o consumo, o que torna um círculo vicioso de retração econômica.

Vale também lembrar as punições previstas no artigo 109 (BRASIL, 2016) para o caso de extrapolação do teto de gastos, que penalizam sempre os trabalhadores, públicos e privados, e a população, que necessita de serviços públicos. Para citar alguns exemplos dessas punições pode-se destacar que ficam vedados concessões, a qualquer título, de vantagem, aumento, reajuste ou adequação de remuneração; e criação de cargo, emprego ou função que implique aumento de despesa. Trocando para uma linguagem mais acessível, isso significa a inexistência de reajuste de salários aos servidores públicos e não contratação de novos. Pode parecer que não contratar novos servidores públicos seja mesmo uma boa medida, no entanto isso acarretará uma piora na qualidade dos serviços públicos ofertados para a população.

Outra penalidade refere-se à vedação de reajuste de despesas obrigatórias acima do valor da inflação. Colocando de forma menos técnica, significa que o salário mínimo não terá reajuste acima da inflação. Considerando que o salário mínimo serve de parâmetro para quase todos os salários da iniciativa privada, é o mesmo que congelar 
também os salários dos trabalhadores regidos pela CLT. As penalidades estendem-se à proibição de criação de qualquer nova despesa obrigatória, o que significa, num país tão desigual, deixar de atender as muitas necessidades que a população apresenta.

Além da suspensão do projeto constituinte de 1988, o novo regime fiscal revela uma clara opção por uma antidemocracia econômica, inviabilizando a expansão e até mesmo a própria manutenção de políticas públicas para reservar dinheiro público e garantir o pagamento das obrigações assumidas pelo governo federal brasileiro perante os credores da dívida pública (MARIANO, 2017, p. 262).

No momento de buscar soluções para o equilíbrio das contas públicas sempre é focado na redução do gasto, mas outra medida que poderia ser tomada é o aumento das receitas, e não necessariamente com o aumento de impostos. Medidas como o combate à sonegação, fim de isenções fiscais, taxação de lucros e dividendos ${ }^{13}$ poderiam gerar muito mais receita do que o montante de gastos cortados. Isso, porém, não ocorre gratuitamente. O discurso neoliberal predominante na sociedade prega que é necessário a redução da máquina pública e que o privado é melhor do que o público, como afirma Grabowski (2010):

O neoliberalismo foi tão "eficiente" ideologicamente que chegou a criar um relativo consenso capaz de inviabilizar uma contestação política real e conseqüente. Uma confusão entre o que é indivíduo e o que é privado, somado à idéia de que tudo o que é público é inimigo de cada indivíduo, gerou uma carga ideológica paralisante e desmobilizadora das ações reivindicatórias de direitos (p. 77).

A única forma de reverter a EC no 95/2016 é por meio de uma nova emenda constitucional, o que torna bastante difícil para um novo governo executar. Nesse sentido, Machado Segundo (2017, p. 31) afirma que um novo governo "poderá propor ao Congresso, se for o caso, a elaboração de nova emenda, destinada a modificar ou mesmo extinguir o Novo Regime Fiscal, tendo à sua disposição o mesmo ferramental jurídico usado para instituí-lo". Essa medida, contudo, não seria tão fácil assim de efetivar, pois os interesses do capital, que culminaram na aprovação dessa emenda, não ficarão inertes caso surja uma proposta de substituí-la.

\section{O financiamento da educação profissional e tecnológica}

Neste trabalho foi delimitada a análise ao período pós-Constituição de 1988, uma vez que a Emenda Constitucional no 95/2016 altera seus dispositivos. Para Oliveira e Silva (2018), a Constituição de 1988 prevê para a manutenção e desenvolvimento do Ensino, em seu artigo 212 , a vinculação mínima de $18 \%$ para a União e $25 \%$ para os Estados e municípios. Esses percentuais são calculados sobre a receita de impostos e de transferências. Essa garantia, todavia, refere-se à Educação como um todo, não especificando o que cabe à Educação Profissional.

${ }^{13}$ Lucros e dividendos são o resultado que as empresas possuem em cada ano financeiro e são distribuídos aos seus acionistas; hoje não há desconto de imposto de renda desses recursos. 
Apesar das garantias constitucionais, não havia consenso sobre a concepção de Estado e de Educação que deveriam ser instituídas. Nesse sentido, Ramos (2014, p. 64) afirma que "o Governo Fernando Collor de Mello propôs para o Brasil um modelo de reestruturação econômica e de intervenção do Estado afinado com o ideário neoliberal". A concepção de Estado que o neoliberalismo traz diz muito sobre a importância que a Educação Pública terá no governo, pois cada modelo de Estado traz consigo uma concepção de Educação e da importância de serviços públicos gratuitos e de qualidade. Sobre a constituição da sociedade capitalista brasileira, Ribeiro, Farenzena e Grabowski (2012) ressaltam:

A organização estrutural de uma sociedade capitalista dependente e subordinada, como a brasileira, reflete-se na política e no financiamento da educação. O fato de sermos uma das sociedades com maior concentração de riqueza e uma das mais desiguais do mundo, configurando uma sociedade desigual e injusta, terá como uma das consequências a oferta de educação desigual para classes desiguais e distribuição desigual de recursos (p. 118).

Visando a garantir os recursos necessários para a promoção de uma Educação de qualidade, o atual Plano Nacional de Educação (PNE 2014-2024) prevê, em sua meta 20, até 2024, a destinação de $10 \%$ do PIB para a Educação, o que, segundo Amaral (2017, p. 7), "significa quase que dobrar o volume de recursos financeiros". Cabe salientar que a prioridade dada para o financiamento da Educação revela a concepção de Estado e de sociedade que os agentes que dominam o poder possuem. Investir em uma Educação emancipadora só faz sentido para quem pretende melhorar as desigualdades sociais, não para quem lucra com elas.

Para se ter uma ideia do montante que foi investido em Educação de 1995 a 2016, conforme Amaral (2017, p. 10), "o Poder Executivo teve, em 17 anos do período em análise, de 21 anos, percentuais de reajustes que superaram as inflações dos anos anteriores". Mesmo com um investimento em Educação superior à correção inflacionária, existem muitas demandas não atendidas. Com a EC no 95/2016 esse cenário será ainda mais desolador. Para Amaral (2017, p. 10), "essa limitação comprometerá fortemente a execução de qualquer proposta que se faça para os planos nacionais de Educação futuros e que vigorarão no período de validade da EC 95".

Se o financiamento da Educação como um todo já é preocupante, quando se fala em Educação Profissional o cenário é ainda pior. Segundo Kuenzer e Grabowski (2006, p. 312), "não há, na legislação do Estado brasileiro, a responsabilidade constitucional ou legal de financiamento da Educação Profissional". Esse ramo da Educação tem, todo ano, suas verbas orçamentárias, e, de acordo com Ribeiro, Farenzena e Grabowski (2012, p. 118), "definidas a partir da luta por recursos escassos no processo de elaboração do orçamento geral da união ou programas". Esses Programas, com "aparência" de políticas sociais, mudam a cada governo e priorizam cada hora um setor diferente da sociedade, carecendo de estabilidade nas ações, como afirma Grabowski (2010)

A educação profissional, mesmo ocupando um espaço expressivo nos discursos empresariais e oficiais, propagada no meio empresarial, reivindicada por entidades representativas dos trabalhadores e, freqüentemente, destacada nos meios de comunicação, ainda não possui uma política de financiamento sistemática, perma- 
nente e com recursos correspondentes à relevância que lhe é atribuída. Como exceção, podem ser citadas as alocações orçamentárias, realizadas anualmente por governos, para os programas que entendem ser relevantes ou como meios de repasse de recursos para entidades de natureza privada, tais como: escolas privadas, confederações sindicais (patronais e de trabalhadores), ONGs, OSCIPs, programas corporativos empresariais e Sistema " $S$ " (p. 69).

Além disso, a maioria dos programas instituídos ao longo dos anos destinou-se, ou priorizou, o setor privado e os Estados em detrimento da Rede Federal. Para citar um exemplo, o Fundo de Manutenção e Desenvolvimento da Educação Básica (Fundeb), que se destina ao fortalecimento da Educação Básica como um todo, não contempla a Rede Federal. Segundo Pacheco (2011, p. 87-88), "as ofertas municipais e federais não são abarcadas pelo fundo, assim como não o são os cursos ofertados na forma subsequente ou concomitante ao ensino médio". Para a Rede Federal, portanto, resta disputar recursos com os demais gastos do governo no momento da definição do Orçamento Geral da União.

Para que a Educação Profissional, em especial a Rede Federal, possa ter um plano de expansão e melhoria dos serviços prestados com maior tranquilidade financeira, é fundamental que se crie um fundo que reúna todas as fontes orçamentárias e que o governo federal elabore obrigatoriedades de repasse para esse fundo, além de incluir como beneficiárias todas as instituições que ofertam Educação Profissional. Segundo Pacheco (2011), existe 39 fontes públicas que financiam ações da Educação Profissional. A partir dessa articulação será possível pensar em políticas mais eficientes e duradouras na oferta de Educação Profissional aos jovens brasileiros, desde que haja um comprometimento, por parte do Estado, com a promoção de uma Educação emancipadora.

O Brasil possui, de acordo com Pacheco (2011), quase 30\% de jovens entre 18 e 25 anos de idade sem o Ensino Fundamental completo, aliado à exigência cada vez maior de qualificação no mercado de trabalho. Este cenário demonstra um quadro crítico para a quinta maior população jovem do mundo, segundo o Fundeb. Esses dados demonstram quão longe se está da universalização da Educação Básica, colocando na ordem do dia a ampliação de vagas e condições de acesso às escolas do país. Para, no entanto, que se aumente o número de vagas na Educação Básica, sobretudo na Educação Profissional de nível médio, é fundamental que haja aumento no investimento público para a Educação, mas, infelizmente, se tem um movimento contrário a esta necessidade.

Conforme dados do Conif, a Rede Federal teve redução de recursos de custeio considerável nos últimos anos, fruto das mudanças na política econômica e fiscal do governo, quando a Educação deixou de ter um papel de destaque. Para o mesmo órgão, em 2017 seria necessário para a garantia das atividades institucionais $R \$ 3,7$ bilhões, sendo aprovado pelo MEC o valor de apenas R\$ 2,1 bilhões. No ano de 2014 haviam 415 campi, 673.602 matrículas e R\$ 2.363.732.614,00 de custeio, já em 2017 haviam 606 campi, 878.682 matrículas e $\mathrm{R} \$ 2.188 .537 .801,00$ de custeio, ou seja, aumentou o número de estudantes e o tamanho da estrutura física e reduziram os recursos para custeio. 
Este cenário de redução dos recursos orçamentários para a Rede Federal demonstra um sério risco à manutenção da estrutura física e condições de desenvolvimento das atividades de ensino, pesquisa e extensão necessárias a uma formação politécnica. Sem a garantia de recursos para a ampliação de estrutura física, compra de insumos para aulas práticas e oferta de bolsas de ensino, pesquisa e extensão, fica comprometido o desenvolvimento de atividades fundamentais à educação de qualidade proposta pelos Institutos Federais.

Outro ponto a ser levado em consideração é a possibilidade de contratação, via concurso público, de docentes e técnicos administrativos em número suficiente para o desempenho satisfatório das atividades acadêmicas. Os dados supra tratam apenas dos recursos de custeio, no entanto a EC no 95/2016 abrange todo o gasto com Educação, contemplados também os servidores públicos envolvidos nesta área. A retração dos recursos financeiros gera dois efeitos imediatos no tocante aos servidores da Educação: restringe a contratação de pessoal e limita as possibilidades de melhoria ou manutenção das condições de carreira de quem já é servidor público, gerando precarização e sobrecarga nas condições de trabalho.

A concepção de Educação Profissional não pode estar desvinculada da garantia de recursos para sua efetivação. Oliveira $(2009$, p. 53) afirma que "a questão que ora se coloca diz respeito não apenas a uma concepção de formação profissional e de nível médio a ser implementada, mas fundamentalmente à disponibilidade de recursos para que tal projeto possa tornar-se realidade". Nesse sentido, lutar por uma Educação Profissional politécnica, emancipadora, pública, gratuita, é lutar por mais recursos para a Educação Pública.

\section{CONSIDERAÇÕES FINAIS}

Ao analisar o papel da Educação em uma sociedade é fundamental ter em mente qual é o modelo de sociedade a que esse projeto de educação serve. Dependendo do papel posto à Educação, será determinado o nível de investimento destinado a ela, uma vez que a disputa pelos corações e mentes dos jovens faz parte do jogo de poder da classe dominante. É com essa premissa que se deve analisar os efeitos que a aprovação da Emenda Constitucional no 95/2016 acarretará na Educação e em todo o gasto público, posto que estes ficam reféns de um congelamento que não leva em conta a situação econômica do país ou o crescimento demográfico.

No Brasil, a criação dos Institutos Federais representou um marco na oferta de Educação Profissional de qualidade numa perspectiva emancipadora, tendo a formação humana e para o mundo do trabalho como norte. Essa experiência, inédita no país, só foi possível por meio da destinação de recursos financeiros consideráveis para garantir estrutura física, de pessoal e pedagógica para as atividades de ensino, pesquisa e extensão necessárias a uma educação integral. Com o congelamento dos gastos públicos, no entanto, incluindo os gastos com Educação promovido pela Emenda Constitucional no 95/2016, esse projeto encontra-se ameaçado.

Comprometer um projeto de educação que possui uma perspectiva emancipadora, tendo o trabalho como princípio educativo e a superação da exploração do homem, que tem por norte a construção de uma nova realidade social, faz parte de um pro- 
jeto de Estado $m$ que a emancipação humana não tem vez. Essa ruptura na política de Educação Profissional põe em xeque os avanços obtidos nessa década de construção e consolidação da Rede Federal. A disponibilidade de recursos financeiros é fundamental e imprescindível para a continuidade dos Institutos Federais. O risco de que, a longo prazo, o financiamento da educação pública vá minguando está posto. Cabe aos educadores, estudantes e sociedade civil como um todo colocar-se na perspectiva de rompimento com essa lógica de redução do papel do Estado na sociedade, por meio da organização de movimentos sociais e ampliação dos mecanismos de participação da sociedade na vida política do país.

\section{REFERÊNCIAS}

AMARAL, Nelson Cardoso. Com a PEC 241.55 (EC 95) haverá prioridade para cumprir as metas do PNE (2014-2024)? Revista Brasileira de Educação, [on-line], v. 22, n. 71, p. 1-25, 2017. Disponível em: http:// www.scielo.br/scielo.php?pid=S1413-24782017000400200\&script=sci_abstract\&tIng=pt. Acesso em: 12 jan. 2020.

ANTUNES, Fátima; PERONI, Vera. Reformas do Estado e políticas públicas. Revista Portuguesa de Educação, Braga, v. 30, n. 1, p. 181-216, 2017. Disponível em: http://www.scielo.mec.pt/scielo.php?script=sci_arttext\&pid=S0871-91872017000100009. Acesso em: 9 jan. 2020.

ARAÚJO, Ronaldo Marcos de Lima; FRIGOTTO, Gaudêncio. Práticas pedagógicas e ensino integrado. Revista Educação em Questão, Natal, v. 52, n. 38, p. 61-80, 2015. Disponível em: https://periodicos.ufrn.br/ educacaoemquestao/article/view/7956/5723. Acesso em: 9 fev. 2020.

APPLE, Michael W. Para além da lógica do mercado. Rio de Janeiro: DP\&A Editora, 2005.

BARBOSA FILHO, Fernando de Holanda. A crise econômica de 2014. 2017. Estudos Avançados, São Paulo, v. 31, n. 89, 2017. Disponível em: http://www.scielo.br/scielo.php?script=sci_arttext\&pi$\mathrm{d}=$ S0103-40142017000100051. Acesso em: 15 jan. 2020.

BRASIL. Lei no 11.892, de 29 de dezembro de 2008. Institui a Rede Federal de Educação Profissional, Científica e Tecnológica, cria os Institutos Federais de Educação Profissional, Ciência e Tecnologia e dá outras providências. Brasília: Presidência da República, 2008. Disponível em: http://www.planalto.gov.br/ ccivil_03/_ato2007-2010/2008/lei/l11892.htm. Acesso em: 15 jan. 2020.

BRASIL. Constituição (1988). Emenda constitucional no 95, de 15 de dezembro de 2016. Altera o Ato das Disposições Constitucionais Transitórias, para instituir o Novo Regime Fiscal, e dá outras providências. Brasília: Presidência da República, 2016. Disponível em: http://www.planalto.gov.br/ccivil_03/constituicao/emendas/emc/emc95.htm. Acesso em: 10 jan. 2020.

FRIGOTTO, Gaudêncio. A relação da educação profissional e tecnológica com a universalização da educação básica. In: MOLL, Jaqueline et al. Educação profissional e tecnológica no Brasil contemporâneo. Porto Alegre: Artmed, 2010. p. 25-41.

FRIGOTTO, Gaudêncio. Política e gestão educacional na contemporaneidade. In: FERREIRA, Eliza BartoIozzi; OLIVEIRA, Dalila Andrade (org.). Crise na escola e políticas educativas. Belo Horizonte: Autêntica Editora, 2009. p. 65-80.

FRIGOTTO, Gaudêncio; CIAVATTA, Maria. Educação básica no Brasil na década de 1990. Revista Educação e Sociedade, Campinas, v. 24, n. 82, p. 93-130, 2003. Disponível em: http://www.scielo.br/pdf/es/ v24n82/a05v24n82.pdf. Acesso em: 7 fev. 2020.

GRABOWSKI, Gabriel. Financiamento da educação profissional no Brasil. 2010. Tese (Doutorado em Educação) - Faculdade de Educação, Universidade Federal do Rio Grande do Sul, Porto Alegre, 2010.

HYPÓLITO, Álvaro Moreira. Estado gerencial, reestruturação educativa e gestão da educação. Revista Brasileira de Política e Administração da Educação, Porto Alegre, v. 24, n. 1, p. 63-78, 2008. Disponível em: https://seer.ufrgs.br/rbpae/article/view/19239/11165. Acesso em: 10 fev. 2020.

KUENZER, Acácia Zeneida; GRABOWSKI, Gabriel. Educação profissional. Perspectiva, Florianópolis, v. 24, n. 1, p. 297-318, 2006. Disponível em: https://periodicos.ufsc.br/index.php/perspectiva/article/ view/10762. Acesso em: 5 jan. 2020. 
MARIANO, Cynara. Emenda constitucional 95/2016 e o teto dos gastos públicos. Revista de Investigações Constitucionais, Curitiba, v. 4, n. 1, p. 259-281, 2017. Disponível em: https://www.researchgate.net/ publication/313831062_Emenda_constitucional_952016_e_o_teto_dos_gastos_publicos_Brasil_de_volta_ao_estado_de_excecao_economico_e_ao_capitalismo_do_desastre. Acesso em: 15 jan. 2020.

MACHADO SEGUNDO, Hugo de Brito. Emenda Constitucional 95.2016 e o teto dos gastos públicos. Revista Controle, Fortaleza, v. 15, n. 2. p. 22-40, 2017. Disponível em: https://dialnet.unirioja.es/servlet/ articulo?codigo=6522429. Acesso em: 2 jan. 2020.

OLIVEIRA, Ramon de. Possibilidades do Ensino Médio Integrado diante do financiamento público da educação. Educação e Pesquisa, São Paulo, v. 35, n. 1, p. 51-66, 2009. Disponível em: http://www.scielo.br/ scielo.php?pid=S1517-97022009000100004\&script=sci_abstract\&tlng=pt. Acesso em: 1ㅇ fev. 2020.

OLIVEIRA, Cleiton de; SILVA, Guaracy. O novo regime fiscal. Revista Brasileira de Política e Administração da Educação, v. 34, n. 1, p. 253-269, 2018. Disponível em: https://seer.ufrgs.br/rbpae/article/view/77586. Acesso em: 10 fev. 2020.

PACHECO, Eliezer. Os Institutos Federais: uma revolução na educação profissional e tecnológica. Brasília: Moderna, 2011. Disponível em: https://www.moderna.com.br/lumis/portal/file/fileDownload.jsp?fileld=8A7A83CB34572A4A01345BC3D5404120. Acesso em: 13 jan. 2020.

PAULA, Ana Paula Paes de. Administração pública brasileira entre o gerencialismo e a gestão social. Revista de Administração de Empresas, São Paulo, v. 45, n. 1, p. 36-49, 2005. Disponível em: https://rae.fgv.br/ rae/vol45-num1-2005/administracao-publica-brasileira-entre-gerencialismo-gestao-social. Acesso em: 7 fev. 2020.

PERONI, Vera Maria Vidal; CAETANO, Maria Raquel. O público e o privado na educação. Revista Retratos da Escola, Brasília, v. 9, n. 17, p. 337-352, 2015. Disponível em: http://retratosdaescola.emnuvens.com. br/rde/article/viewFile/584/658. Acesso em: 10 fev. 2020.

PERONI, Vera; SCHEIBE, Leda. Privatização da e na educação. Revista Retratos da Escola, Brasília, v. 11, n. 21, p. 387-392, 2017. Disponível em: http://retratosdaescola.emnuvens.com.br/rde/article/view/831. Acesso em: 9 jan. 2020.

PIRES, Daniela de Oliveira; PERONI, Vera Maria Vidal. A história da educação brasileira sob o enfoque da relação público-privada. Revista Contrapontos, Itajaí, v. 20, n. 2, p. 10-27, 2019. Disponível em: https:// siaiap32.univali.br/seer/index.php/rc/article/view/13845. Acesso em: 10 fev. 2020.

RAMOS, Marise. Ensino médio integrado. In: MOLL, Jaqueline et al. Educação profissional e tecnológica no Brasil contemporâneo. Porto Alegre: Artmed, 2010. p. 42-57.

RAMOS, Marise. História e política da educação profissional. Curitiba: Instituto Federal do Paraná, 2014. Disponível em: https://curitiba.ifpr.edu.br/wp-content/uploads/2016/05/Hist\%C3\%B3ria-e-pol\%C3\%ADtica-da-educa\%C3\%A7\%C3\%A3o-profissional.pdf. Acesso em: 7 jan. 2020.

RIBEIRO, Jorge Alberto Rosa; FARENZENA, Nalú; GRABOWSKI, Gabriel. Financiamento da educação básica e profissional. Indic. Econ. FEE, Porto Alegre, v. 39, n. 3, p. 111-124, 2012. Disponível em: https://revistas. fee.tche.br/index.php/indicadores/article/view/2638. Acesso em 20 jan. 2020.

ROSSI, Pedro; DWECK, Esther. Impactos do Novo Regime Fiscal na saúde e educação. Cadernos de Saúde Pública, Rio de Janeiro, v. 32, n. 12, 2016. Disponível em: http://www.scielo.br/pdf/csp/v32n12/16784464-csp-32-12-e00194316.pdf. Acesso em: 14 jan. 2020.

SANDER, Benno. Políticas públicas e gestão democrática da educação. Brasília: Liber Livro, 2005.

SOARES, Laura Tavares. Os custos sociais do ajuste neoliberal na América Latina. São Paulo: Cortez, 2009. SOUZA, Nilson Araújo de. Economia brasileira contemporânea. São Paulo: Atlas, 2008.

TEODORO, António. A educação em tempos de globalização neoliberal. Brasília: Liber Livro, 2011. 